\title{
As dimensões constitutivas da Pedagogia como campo de conhecimento ${ }^{1}$
}

\author{
Maria Amélia Santoro Franco ${ }^{2}$ \\ ameliasantoro@uol.com.br \\ José Carlos Libâneo \\ libaneojc@uol.com.br \\ Selma Garrido Pimenta ${ }^{4}$ \\ sgpiment@usp.br
}

\section{Resumo}

No texto discute-se a especificidade epistemológica do campo científico e profissional da Pedagogia, definindo-o como a teoria e a prática da educação, compreendendo educação em seu sentido lato e pluridimensional. Desse modo, a variedade de práticas educacionais na sociedade resulta numa diversidade de práticas pedagógicas, entre elas a educação escolar. Afirma-se a distinção entre Pedagogia e Didática, aquela com maior amplitude conceitual do que esta, em que a docência se apresenta como modalidade peculiar da atividade pedagógica. Partindo-se da compreensão da práxis educativa - como objeto da ciência pedagógica - como ação intencional, reflexiva e transformadora dessa práxis, são explicitadas três dimensões da Pedagogia, a epistemológica, a prática e a disciplinar.

Palavras-Chave: epistemologia da Pedagogia; práxis educativa; Pedagogia e Didática; Teoria Pedagógica.

1 Este texto foi apresentado com modificações na Conferência de Abertura do IV Fórum Nacional de Pedagogia (FONAPE), proferida por Selma Garrido Pimenta em 21 de setembro de 2011, em Belo Horizonte.

2 Profa. Titular da Universidade Católica de Santos - UniSantos.

3 Prof. Titular da Universidade Católica de Goiás - UCG.

4 Profa. Titular da Universidade de São Paulo - USP.

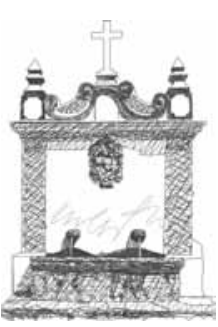




\section{Considerações iniciais}

A Pedagogia como teoria, campo investigativo ou atividade prática está, hoje, longe de obter uma posição de consenso sobre seu significado, dificultando sobremaneira a definição do que seria a essência do proceder pedagógico. $\mathrm{Na}$ tradição da investigação pedagógica na Alemanha desde Comênio e Herbart, refletida de alguma forma em outros países europeus como a Itália e a Rússia, e de modo direto na Pedagogia católica, a missão da Pedagogia está na formação mental, moral e estética do indivíduo em sua vida subjetiva e social. Herbart perguntava em uma de suas obras: "o que pode chegar a ser o sujeito particular que procura educação?" (2003, p. 24). Trata-se de educar os indivíduos para o desenvolvimento de sua individualidade, de sua autonomia, de seu autogoverno, de modo a se fortalecerem contra o domínio unilateral de fins objetivos postos pelo Estado, pela Igreja, pela ciência, pelas classes sociais.

O critério pedagógico que vai persistindo nos pedagogos clássicos como Rousseau, Pestallozi, Montessori continua sendo a formação do ser humano, agora reconhecidas as diferenças entre adulto e criança. Em concordância com Herbart, H. Nohl (1948) acrescenta, dentro da concepção historicista, que tudo o que for exigido da criança pela cultura objetiva e pelas relações sociais vigentes em dada sociedade precisa subordinar-se ao seguinte critério: que sentido têm estas exigências em conexão com a vida desta criança para sua formação e para o enriquecimento de suas forças, e que meios possui esta criança para satisfazê-las. Revela-se nisso a tensão entre o individual e o social, entre a subjetividade e as condições e fins objetivos postos pela sociedade. Nessa polaridade se entrecruzam as diversas situações e atos pedagógicos. Escreve Nohl:

A criança não é meramente um fim em si, ela também está sujeita às estruturas e fins objetivos para os quais é educada. Tais estruturas não são apenas meios educativos para a estrutura individual; elas têm seu 
próprio valor, de modo que a criança não pode ser educada apenas para si, mas também para o trabalho cultural, para a profissão e para a comunidade nacional (NOHL, 1948, p. 42).

A compreensão de Pedagogia legada pelos clássicos está, portanto, vinculada à ação formativa ou educativa em todas as circunstâncias da vida, de modo que a Educação expressa a forma do desenvolvimento humano em contextos culturais. Também as concepções críticas da Educação, entre elas as inspiradas no marxismo, sem retirar da Educação sua missão de formação do indivíduo, destacam a estreita vinculação da Educação com a sociedade, ressaltando o caráter político-social da Educação e mantêm a tradição da especificidade da ciência pedagógica. ${ }^{5}$

Em desacordo com o tom notoriamente axiológico e prescritivo da Pedagogia geral, devido à incompatibilidade com a visão cientificista e pragmática, estudiosos da Educação, na segunda metade do século XIX, tanto na França como nos países de língua inglesa, pretenderam afirmar a cientificidade da Educação ao entender que os fatos humanos podem ser investigados dentro do paradigma científico positivista, desvinculados de juízos de valor e prescrições (DURKHEIN, 1985). A Pedagogia passa a ser pensada como ciência, ao modo de outras ciências positivas, e, conforme Dewey (1968), nos países anglo-saxônicos, o termo Pedagogia é substituído por Ciência da Educação ${ }^{6}$. Anuncia-se já aí a necessidade do concurso da Psicologia, da Sociologia, da História para dar substância ao estudo do fenômeno educativo e superar a ideia de Pedagogia apenas como relação educador-aluno ou da Pedagogia dos conselhos humanistas edificantes, o que resultou mais tarde na adoção do termo Ciências da Educação e sua

5 Tal afirmação encontra respaldo em Suchodolsky (1977; 1979), Schimied-Kowarzik (1983), Visalberghi (1983), entre outros autores.

6 A Pedagogia científica e a Pedagogia experimental, segundo Cambi, "vêm delinear um novo modelo de Pedagogia, radicalmente inovador no seu estatuto epistemológico e aberto a um crescimento cumulativo como é o das ciências empíricas; a Pedagogia liga-se, assim, à lógica da ciência como também se nutre de sua ideologia, mas se consolida como um dos saberes-chave da modernidade [...]" (CAMBI, 1999, p. 501).

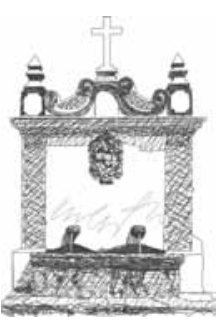


introdução como disciplina na universidade em 1967. Ou seja, o fenômeno educativo deverá ser compreendido também em sua contextualização histórica, social e institucional; ele não poderia ser objeto de uma disciplina, mas de um conjunto de disciplinas.

Na França, foi se constituindo também a concepção de Pedagogia como teoria e prática do ensino, muito próxima do que na tradição brasileira herdada da Alemanha conhecemos por Didática. Por exemplo, Altet assim define a Pedagogia:

O campo da transformação da informação em saber pela mediação do ensino, pela comunicação, pela ação interativa numa situação educativa dada. [...] A Pedagogia concorre para a transformação da informação em Saber pelas mudanças cognitivas e socioafetivas, dos métodos postos em prática pelo professor por meio de interações, retroações (sic), de modos de ajustamentos, de adaptações interpessoais que facilitam e permitem a aprendizagem durante o tempo real da intervenção (ALTET, 1997, p. 11).

O pedagogo, então, é o que facilita a transformação da informação em saber por meio de uma prática relacional e da ação do professor na sala de aula, organizando situações pedagógicas para o aprendiz, ou seja, formas de comunicação que favoreçam a aprendizagem dos alunos. Já a Didática, para essa mesma autora, trata da estruturação do saber e gestão dos conteúdos pelo professor e de sua apropriação pelo aluno. As formas de gestão dessa articulação dialética ensinaraprender podem ser realizadas de maneira diferente, originando-se daí as distintas correntes pedagógicas.

Com base nessa noção de Pedagogia e Didática e, principalmente, para romper com um tipo de Pedagogia ora edificante, ora demasiamente prescritiva, e até com os excessos psicologizantes tomados pela Psicopedagogia, desenvolvem-se, também, na França, ao final dos anos 1960, as didáticas das disciplinas escolares voltadas basicamente para as questões de ensino e aprendizagem de conteúdos de uma disciplina. Em anos recentes, em meio à 
polêmica mal resolvida entre os franceses sobre os significados de Pedagogia, Ciências da Educação e Didática, surgiu um grupo de "novos pedagogos"7. Entre esses, Houssaye (2004, p. 12) define a Pedagogia como uma reflexão sobre a prática educativa, articulando na ação pedagógica a teoria e a prática: “o que deve haver em Pedagogia é certamente uma proposta prática, mas ao mesmo tempo uma teoria da situação educativa referida a essa prática, ou seja, uma teoria da situação pedagógica" ${ }^{8}$.

No Brasil, certamente se fazem presentes todos os significados considerados em relação ao estudo da educação, já que nossas concepções de educação são herdadas de várias culturas e de várias tradições epistemológicas, europeias ou norte-americanas. Conforme escreve acertadamente Hameline (2005, p. 707), "uma palavra como Pedagogia, independentemente do que se diga ou se faça, é produto de uma cultura...". É assim que em nossas instituições de formação de educadores incidem posições que identificam os estudos sobre o fenômeno educativo, ora como Pedagogia geral (Ciência Pedagógica), ora como Ciência da Educação ou Ciências da Educação e até a identificação da Pedagogia com o ensino.

Uma breve incursão na história da educação brasileira mostraria que, até o início dos anos 1980, dominava o entendimento da Pedagogia como ciência da educação, devido à forte influência da educação católica na concepção dessa disciplina ${ }^{9}$. A movimentação política ocorrida no Brasil nessa mesma década provocou o

7 Designação dada por Hameline a um grupo de investigadores que se voltam para a Pedagogia no seu sentido de "teoria prática", mencionando, entre outros, Philippe Perrenoud, Philippe Mieirieu, Jean Houssaye, Charles Hadji, Francis Imbert (HAMELINE, 2005, p. 712).

8 Para Houssaye, a Pedagogia e a didática, mais do que campos complementares, são uma e mesma coisa, como demonstra em seu artigo "Didactique et pedagogie: l'illusion de la difference - l'exemple du triangle" (1995). Embora não seja essa a posição que defenderemos neste texto, ao menos ela possibilita evitar a diferenciação artificial frequentemente encontrada em autores franceses, como Altet e Joannaert. Por exemplo, para Joannaert, "a visão do pedagogo permite compreender a dinâmica das interações entre os alunos. [...] o didata tenta antes compreender os conhecimentos que são veiculados nesse diálogo" (JOANNAERT, 2002, p. 63). Ora, precisamente é dessa ilusão de separação entre Pedagogia e Didática que se ocupa Houssaye em seu artigo.

9 É relevante, no Brasil, considerar a influência da Pedagogia católica na formulação do referencial teórico e científico da Pedagogia, fortemente inspirado nos pedagogos clássicos alemães a partir de Herbart, do que é um exemplo a obra de Otto Willmann (1970). A presença da Pedagogia católica, da Pedagogia de Herbart e da Pedagogia marxista na história da educação brasileira é investigada amplamente em Libâneo (1990).

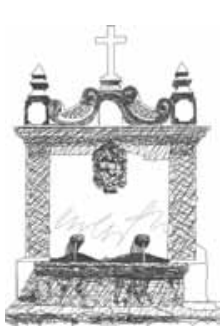

59

Ano 14 - n. 17 - julho 2011 - p. 55-78 
questionamento do formato curricular dos cursos de formação de professores provocado, em boa medida, pela introdução do pensamento marxista na Educação associada à incorporação da teoria da reprodução de Bourdieu e Passeron e da teoria dos aparelhos simbólicos de Estado de Althusser, conforme nos indica Saviani (1983). Nesse momento, a Pedagogia é criticada pelo seu lado "reprodutor", conservador, razão que levou algumas instituições formadoras a assumir a formulação francesa de "Ciências da Educação".

Em pouco tempo, essa formulação perdeu espaço e, por influência da teoria marxista da divisão do trabalho, os estudos pedagógicos sistematizados foram substituídos por estudos sobre docência, assumindo-se que a base da formação de todo educador é a docência (ENCONTRO NACIONAL DA ANFOPE, 6., 1992, Belo Horizonte) ${ }^{10}$. No contexto da polêmica que se abriu no país, sobre a ênfase a ser dada nos currículos de formação de professores, adversários dessa posição criticaram, nas propostas da ANFOPE, o enfraquecimento dos estudos pedagógicos, uma vez que os cursos de Pedagogia deixaram de formar o "pedagogo" em sentido estrito e passaram a formar, exclusivamente, o professor para a educação infantil e séries iniciais do ensino fundamental ${ }^{11}$.

Assumimos a Pedagogia como um campo de estudos sobre o fenômeno educativo, portadora de especificidade epistemológica que, ao possibilitar o estudo do fenômeno educativo, busca a

10 Observe-se que, a despeito da crítica que aqui se faz à redução do curso de Pedagogia a um curso de formação de professores, a identificação da Pedagogia com a docência não é uma criação dos militantes da ANFOPE. Embora os militantes dessa associação não justifiquem sua tese pela experiência francesa, é fato que na França desenvolveu-se e se mantém uma definição de Pedagogia que a aproxima da docência. Vimos, anteriormente, que M. Altet define Pedagogia como a ação na sala de aula. Em outro lugar, ela escreve: "O professor-profissional é antes de tudo um profissional da articulação do processo de ensino-aprendizagem em situação, um profissional da interação de significações partilhadas" (JONNAERT, 2002, p. 42). Ora, se a Pedagogia atua na interação professor-alunos e na gestão da situação pedagógica, então o professor seria um pedagogo, e o curso de formação desses professores seria o curso de Pedagogia (ENCONTRO NACIONAL DA ANFOPE, 6., 1992, Belo Horizonte).

11 A ANFOPE foi a associação profissional que resultou de movimento encetado por professores e pesquisadores em favor de mudanças na legislação sobre formação de educadores. Após mais de 20 anos de debates em meio à polêmica sobre a natureza do curso de Pedagogia, as teses da ANFOPE foram incorporadas integralmente pela Resolução n. 1 do Conselho Federal de Educação, de 2005, que legisla sobre as diretrizes curriculares do curso de Pedagogia.

Ano 14 - n. 17 - julho 2011 - p. 55-78 
contribuição de outras ciências que têm a Educação como um de seus temas. Assim, a Pedagogia é a ciência que tem por objeto a educação humana nas várias modalidades em que se manifesta na prática social. Trata-se, pois, da ciência da educação que investiga a natureza do fenômeno educativo, os conteúdos e os métodos da Educação, os procedimentos investigativos. Entendemos que a Educação, em suas várias modalidades, se caracteriza como processo de formação das qualidades humanas, enquanto que o ensino é o processo de organização e viabilização da atividade de aprendizagem em contextos específicos para esse fim.

Em síntese, o termo Pedagogia designa um determinado campo de conhecimentos com especificidade epistemológica, cuja natureza constitutiva é a teoria e a prática da Educação ou a teoria e a prática da formação humana, e a Didática, o ramo da Pedagogia que trata do processo de ensino e aprendizagem. Desse modo, a formação profissional de pedagogos extrapola o âmbito escolar formal devendo abranger, também, esferas mais amplas da Educação, a não-formal e a informal, ou seja, toda atividade docente é atividade pedagógica, mas nem toda atividade pedagógica é necessariamente atividade docente.

Para além do dilema posto entre o pedagogo que faz escola e o pedagogo que pensa a Educação, avançamos para um entendimento mais interativo dessas posições, aproximando-nos da posição de Houssaye (2004) sobre o trabalho de pedagogo: aquele que procura conjugar a teoria e a prática, a partir de sua própria ação. Trata-se de uma posição em que a Pedagogia é por um lado ciência, mas, por outro, arte e também uma orientação para a ação educativa, ou seja, na expressão de Hameline (2005, p. 710), "um misto de idéias (sic) e de experiência, de constatação e de contestação, de rejeição e projeto", ou seja, uma teoria prática, da qual se socorre a Didática.

Portanto, cumpre registrar que nossa compreensão opõe-se à posição dominante entre os educadores da ANFOPE e também à recente legislação que define as diretrizes curriculares nacionais

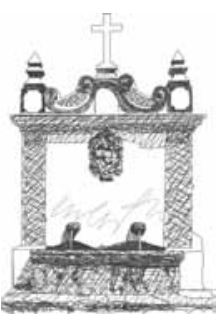


para os cursos de Pedagogia, elaborada com base nas propostas dessa Associação.

\section{A dimensão epistemológica}

A dimensão epistemológica da Pedagogia refere-se à definição do seu objeto, de seus procedimentos investigativos, dos requisitos que a constituem como ciência. Recorrendo a Mialaret (1991, p. 9), a Pedagogia "é uma reflexão sobre as finalidades da educação e uma análise objetiva de suas condições de existência e de funcionamento. Ela está em relação direta com a prática educativa que constitui seu campo de reflexão e análise, sem, todavia, confundir-se com ela". Na tradição das teorias sociocríticas, a prática educativa constitui-se sempre como prática social, e, no caso da Pedagogia, uma prática social humanizadora. A Educação, assim, seria uma ação e um processo de possibilitar aos sujeitos realizarem-se como seres humanos, portanto, inseridos no processo civilizatório.

A Pedagogia apresentou, historicamente, configurações que demarcaram sutis diferenças em sua abrangência, mas profundas alterações em sua epistemologia. Uma das razões dessas alterações (em sua epistemologia) é o fato de ter sido teorizada por diferentes óticas científicas, conferindo-lhes quer uma multiplicidade de abordagens conceituais, quer diferentes configurações reducionistas de sua especificidade e de sua possibilidade como ciência na construção do conhecimento pedagógico, frequentemente descaracterizando seu status de ciência, e até criando a sensação de sua desnecessidade como espaço científico fundamentador da práxis educativa.

No caso brasileiro, esse cenário histórico retirou a Pedagogia do palco, desprestigiou o protagonismo dos pedagogos e, em seu lugar, foram se instalando os tecnólogos da prática, que foram, aos poucos, reduzindo o objeto específico de investigação dessa ciência, qual seja, a educação concretizada em práticas educativas. Ao invés disso, seu objeto foi focando apenas os 
aparatos tecnológicos do processo de instrução e, dessa forma, a formação docente passou a ser apropriada como treinamento de habilidades, o que contribuiu para apequenar a função social dos professores, que passaram a ser tratados como mero ensinadores, de conteúdos arbitrária e previamente selecionados.

O crescimento desses significados e representações das finalidades da Educação, que supervalorizaram a organização da instrução e subestimaram os destinos e valores educativos, levaram ao enfraquecimento e à alteração da identidade da Pedagogia, fazendo-a distanciar-se de seus ideais político-transformadores e encerrando-a nas salas de aula, onde seu papel passou a ser apenas o de racionalizar ações para qualificar a eficiência do ensino, na perspectiva instrumental. Nesse sentido, a Pedagogia foi sendo subsumida à docência e, assim, como enfatiza Libâneo (1998, p. 126), "a formação pedagógica foi significando, cada vez mais, a preparação metodológica do professor e, cada vez menos, campo de investigação sistemática da realidade educativa. Estes fatos deram espaço para aprofundar o dilema já referido entre o pedagogo que faz escola e o pedagogo que pensa a educação".

À medida que a ciência pedagógica foi sendo considerada como a ciência da organização da instrução educativa, numa configuração que se pode denominar técnico-científica e, diga-se, sua mais forte e talvez consensual representação, sua atuação foi se tornando instrumental, tecnicista, tecnológica. Distanciou-se dos sentidos da intencionalidade da prática e centrou-se no que Carr (1996) denomina de tecnologia da prática, utilizando-se do conceito de poiesis para expressar um saber fazer não reflexivo que destrói a imanência da intelegibilidade da práxis, impedindo a interpretação dessas práticas e a possibilidade de integrar sujeito e ação, ampliando os vácuos decorrentes da não articulação de teorias com as práticas referentes.

Quando a ciência pedagógica incorpora a possibilidade de vincular-se ideologicamente à realidade educacional, construindose como um saber alinhado, ou um saber engajado, numa abordagem

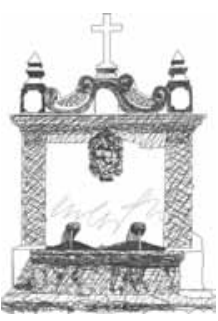


que se pode denominar de crítico-emancipatória, realça-se a focalização da práxis educativa como objeto dessa ciência num movimento que integra intencionalidade e prática docente; formação e emancipação do sujeito da práxis. A Pedagogia assim assumida permite vislumbrar a construção de passarelas articuladoras entre as teorias educacionais e as práticas educativas. Nessa perspectiva, a Pedagogia revela-se como uma ação social de transformação e de orientação da práxis educativa da sociedade, onde desvela as finalidades político/sociais presentes no interior da práxis e reorienta ações emancipatórias para sua transformação.

Sabe-se da enorme complexidade desse objeto, e sabe-se também que a educação configura-se, estabelece-se, estrutura-se em diversas dimensões. Sua dimensão privilegiada é a prática educativa, vista como prática social intencionada. Nela confluem as intencionalidades e as expectativas sociais em que se determinam os contextos da existência humana num determinado grupo social, no qual se concretiza a realidade subjetivada, num processo históricosocial que se renova continuamente. Assim, consideramos que o objeto da Pedagogia como ciência será a práxis educativa. A práxis da educação será assim apreendida como a realidade pedagógica a ser investigada, práxis que é ativa, é vida, que dá movimento à realidade, transforma-a e é por ela transformada.

Os estudos que historicamente tivemos sobre a prática educativa, que se utilizaram de metodologias que desconsideravam a realidade da práxis, informaram-nos sobre a tecnologia da prática, sobre as ações visíveis e observáveis dessa prática, sobre impressões que se construíram sobre o visível das práticas. Mas seu sentido latente, dinâmico, elaborado e transformador em processo não foi captado. Utilizou-se outro conceito da práxis, tal como mostrou Kosik (1976, p. 218): “a práxis se identificou com a técnica, no sentido mais amplo da palavra, e foi entendida e praticada como manipulação, técnica do agir, arte de dispor de homens e coisas, em suma, como poder e arte de manipular o material humano ou as coisas". Entender o sentido de práxis como transformação e criação 
é compreender um novo sentido de homem, absorver uma nova concepção de mundo e poder vislumbrar uma nova dimensão ao campo conceitual da Pedagogia.

A práxis educativa, objeto da ciência pedagógica, caracteriza-se, assim, pela ação intencional e reflexiva de sua prática. Ela é distinta de outras práticas sociais, que até podem funcionar, em certos momentos, como práticas educativas, mas que prescindem dessas condições e que, por não serem organizadas intencionalmente, não serão objeto de estudo da Pedagogia, apesar de estarem incluídas no contexto amplo da Educação. A práxis educativa ocorre prioritariamente em locus formais, especialmente na escola, mas não exclusivamente, pois ocorre na família, pode acontecer no trabalho, nos processos de comunicação social, entre muitos, onde houver uma intencionalidade a se concretizar, permeada por um processo reflexivo de fins e meios.

A ação teórico-prática dessa ciência, a Pedagogia, sobre seu objeto, que é a práxis educativa, poderá ser compreendida como a práxis pedagógica. A práxis pedagógica será o exercício do fazer científico da Pedagogia sobre a práxis educativa, onde quer que ela aconteça. Assim, poderemos estabelecer que o objeto da Pedagogia, como ciência da educação, será o esclarecimento reflexivo e transformador dessa práxis.

Para bem compreender esse entendimento, será necessário pressupor que:

a) a cada práxis educativa corresponde uma teoria implícita que fundamenta essa práxis; o mesmo ocorrerá com a práxis pedagógica; b) as práticas educativas e pedagógicas só poderão ser transformadas a partir da compreensão dos pressupostos teóricos que a organizam e das condições dadas historicamente;

c) a prática, como atividade sócio-histórica e intencional, precisa estar em constante processo de redirecionamento, com vistas a se assumir em sua responsabilidade social crítica;

d) caberá à Pedagogia, como ciência da educação, ser a interlocutora interpretativa das teorias implícitas na práxis e também a mediadora

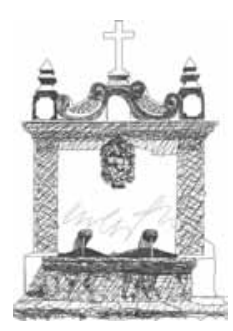


de sua transformação, para fins cada vez mais emancipatórios.

Caberá à Pedagogia ser a ciência que transforma o senso comum pedagógico, a arte intuitiva presente na práxis, em atos científicos, sob a luz de valores educacionais, garantidos como relevantes socialmente em uma comunidade social.

A Pedagogia, assim constituída, poderá superar a dualidade inicial entre ser arte ou ciência da educação para ser a ciência que transforma a arte da educação, o saber fazer prático intuitivo em ação educativa científica, planejada, intencional. Há de se realçar que a realidade da prática educativa se faz por meio de ações artesanais, espontâneas, intuitivas, criativas, que vão se amalgamando, em cada momento de decisão, em ações refletidas, apoiadas em teorias, organizadas por intermédio de críticas, autocríticas, de expectativas de papel. Nesse sentido, no exercício da prática educativa, convivem dimensões artísticas e científicas expressas pela dinâmica entre o ser e o fazer, entre o pensar e o realizar, entre o poder e o querer realizar.

A Pedagogia como ciência deverá se exercer sem descaracterizar seu objeto de estudo, portanto, sem deixar de considerar, na práxis educativa, a presença concomitante, atávica, imanente da ciência e da arte. Cabe-lhe cientificar essa situação esclarecendo, respeitando, desvelando, dando oportunidades para transformações desse universo da prática educativa. Pode, assim, requisitar seu espaço de sua autonomia como ciência, pois para realizar essa tarefa, ela terá que possuir um sistema único, mas não estático, de fundamentos, metodologias e ações próprias, no qual estarão incluídos saberes de diversas ciências.

Como ciência, espera-se que a Pedagogia organize fundamentos, métodos e ações para retirar da práxis a teoria implícita e cientificála a posteriori, juntamente com seus protagonistas, dentro de uma ação crítica pautada na responsabilidade social de uma prática pedagógica. Essa ação requer a autonomia do olhar pedagógico, mas carece de todos os saberes "explicativos" de outras ciências.

Dessa forma, resgata-se à Pedagogia não apenas seu espaço 
de autonomia, mas e principalmente seu caráter essencial de ciência crítico-reflexiva que, consideramos, foi-lhe tirado quando da emergência da cientificidade moderna, que impregnou o fazer educativo-pedagógico com estratégias que visavam um "modo correto de fazer as coisas" ou, mais tarde, na busca de "competência técnica", distanciando dela sua possibilidade de se fazer ciência da práxis para a práxis, por meio de um processo contínuo de reflexão transformadora. A prática foi se transformando em aplicação de modos de fazer, cativa da teoria, cabendo à Pedagogia, historicamente, escolher culpados de um processo educativo fracassado e sobre eles elaborar teorias...

Nesse caminhar, na construção intermediada entre práxis e epistemologia, a Pedagogia precisa enfrentar e superar alguns dilemas e confrontos que foram se impondo historicamente. Este momento histórico requer o enfrentamento dos dilemas de forma lúcida e corajosa, buscando a reinvenção da profissionalidade pedagógica, criando novas condições de humanização das práxis e de convivência solidária com as gerações futuras.

\section{Dimensão prática - A Pedagogia como saberes}

Consideramos que o conhecimento prático resulta de uma conjugação de saberes necessários à ação, que se organizam e se reconstroem dialeticamente com o conhecimento teórico, num processo crítico interpretativo que vai se estabelecendo nas relações sujeito-existência. Clandinin (1986) considera que a concepção de conhecimento prático pessoal é a de um conhecimento experimental, carregado de valor e orientado para a prática. $\mathrm{O}$ conhecimento prático pessoal vai se construindo num processo histórico, o que implica contínuas transformações e, assim, não pode ser entendido como algo fixo, objetivo e sem alteração... Diz o autor que "o conhecimento prático pessoal implica um ponto de vista dialético entre a teoria e a prática" (CLANDININ, 1986, p. 20).

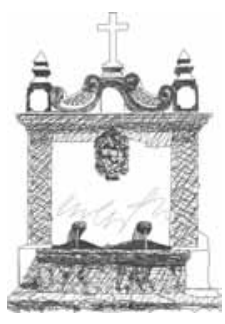


Consideramos, ainda, que os conhecimentos educacionais constituídos nem sempre expressaram essa realidade complexa do fenômeno educativo, ou melhor, esse processo marcado pela dialética do fazer e fazer-se em situação. As teorias educacionais, muitas vezes, não traduziram o sentido implícito das práticas cotidianas e, assim, nem sempre essas teorias atribuíram sentido ao saber-fazer dos educadores, impedindo a possibilidade de utilização dessas teorias como suporte enriquecedor das ações práticas educativas.

A teoria que o sujeito leva à prática nem sempre é a teoria estruturada como conhecimento pedagógico. Essa situação foi se dando pelas dissonâncias que, historicamente, marcaram os desencontros das três dimensões da Pedagogia que aqui analisamos. Talvez esteja aí uma possível explicação da grande distância que foi se estabelecendo entre a teoria e a prática educativa. Ou seja, os estudos científicos sobre a Educação, de cunho positivista, ao se utilizarem de olhares e suportes científicos, característicos de outras ciências, separaram sujeito e objeto de pesquisa, desprezaram as subjetividades inerentes à ação humana, distanciaram os interesses entre pesquisadores e pesquisados, recortaram artificialmente o contexto da pesquisa deixando, portanto, de apreender a essência do sentido dessas práticas, congelando interpretações fragmentadas. Essas interpretações, captadas de forma parcial pelo olhar redutor dos pressupostos da ciência clássica, retiraram da cena educativa o significado original das práticas, expresso e vivido pelos protagonistas, impedindo que os resultados desse trabalho científico fossem percebidos pelos sujeitos como expressão de sua ação. Ou seja, conforme o pedagogo Söetard (2004, p. 51), "as ciências da educação continuam sendo construções teóricas que não conseguem encontrar a passagem para o real e instrumentar realmente a prática".

Essa situação da inadequação histórica dos suportes científicos da Pedagogia produziu muita dificuldade na interpenetração da teoria com as práticas educacionais, impedindo a fertilização 
mútua entre os dois polos da atividade educativa, reafirmando a esterilidade de muitas teorias e a inadequação de muitas práticas. Sabe-se que, quando os sujeitos não constroem sentido, não conseguem realizar a apreensão cognitiva/emocional dos conhecimentos teorizados e, assim, não percebem a relação entre os conhecimentos teóricos e suas ações cotidianas.

Ao considerar a fragmentação de saberes na formação de professores e as flutuações de sentido da Pedagogia como ciência, que ao restringir-se ao campo aplicado das demais ciências perde seu significado de ciência prática da prática educacional, Houssaye (1995) aponta como caminhos de superação a necessidade de que os educadores se empenhem em construir saberes pedagógicos a partir de necessidades pedagógicas postas pelo real, para além dos esquemas apriorísticos das ciências da educação. $\mathrm{O}$ retorno à Pedagogia só ocorrerá se as ciências da educação deixarem de partir de diferentes saberes constituídos e começarem a tomar a prática dos profissionais como o ponto de partida e de chegada. Portanto, só há um caminho: reinventar os saberes pedagógicos a partir da prática social da Educação. Nesse sentido, Pimenta (1999) afirma que os saberes sobre a Educação e sobre a Pedagogia não geram os saberes pedagógicos. Estes só se constituem a partir da prática que os confronta e os reelabora. Mas os práticos não os geram apenas com o saber da prática.

As práticas pedagógicas se apresentam na educação com estatuto frágil, sendo reduzidas a objetos de análise de diferentes perspectivas: histórica, psicológica, antropológica etc. É preciso conferir-lhes um estatuto epistemológico. A Pedagogia, integrando as três dimensões que tratamos neste texto, poderá preocupar-se com as possibilidades de construção de teorias, a partir da prática, criando estratégias didáticas e investigativas que auxiliarão na composição de possíveis saberes pedagógicos que poderão servir de apoio para a compreensão e transformação das práticas.

Franco (2006) considera que os saberes pedagógicos só são possíveis em um sujeito que vai gradativamente assumindo

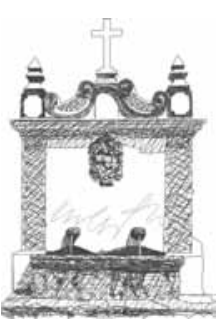


uma posição política frente ao compromisso de ser professor, engajando-se criticamente em suas circunstâncias, cercando e acercando-se de sua realidade existencial, transformando-a em direção às suas intencionalidades. Assim, esse sujeito vai fazer uso do necessário conhecimento didático, metodológico, cultural, servindo-se desse aparato teórico-prático para ir construindo em ação seus saberes disciplinares, didáticos, metodológicos. A capacidade de articular o aparato teórico-prático, a capacidade de mobilizá-lo na condição presente, a capacidade de organizar novos saberes a partir da prática, essas capacidades em conjunto estruturam aquilo que chamamos de saberes pedagógicos.

A Pedagogia como ciência precisará assimilar o papel de integradora e disponibilizadora dos saberes produzidos pelos práticos, promovendo a situação comunicativa proposta por Habermas a partir de uma perspectiva emancipatória, ou seja, valorizando os saberes dos práticos, permitindo-lhes criar e transformar o sentido de seu cotidiano. Para tanto, requer-se da Pedagogia como ciência um caráter de autorreflexão que inclui sempre a crítica por princípio e a intersubjetividade como ponto de partida na compreensão da subjetividade, tendo como finalidade emancipar o sujeito da opressão da racionalidade burocrática dos sistemas escolares.

\section{A dimensão disciplinar - A Pedagogia como curso}

As dimensões apresentadas vão constituindo, em cada tempo e lugar, a dimensão disciplinar à medida que formam o conteúdo dos estudos pedagógicos, antes de tudo o que diz respeito à natureza e aos elementos constitutivos do fenômeno educativo e, logo, o referente aos saberes da prática. O curso de Pedagogia consolida, pois, aquele conjunto organizado de saberes, arranjados e rearranjados entremeio às exigências de formação geral e formação especializada, ora com disciplinas independentes, ora transversais, dentro da tendência à flexibilidade curricular e à interpenetração de saberes e práticas.

70

Ano 14 - n. 17 - julho 2011 - p. 55-78 
O que são ou devem ser os saberes pedagógicos é assunto já bastante investigado em vários países, resultando em vários mapeamentos, por sua vez reproduzidos no Brasil com maior ou menor criatividade nos formatos curriculares encontrados nos vários cursos de formação de educadores, conforme afirmações de Gauthier, Housseye, Tardif, Franco, Pimenta, entre outros autores. A síntese de Pimenta (1999) - saberes da teoria da educação, saberes sobre relação educação-sociedade, saberes sobre organização da escola e sobre o processo de ensino e aprendizagem - parece contemplar a classificação que tem sido acordada entre os vários autores: saberes teórico-científicos, saberes procedimentais (em parte decorrentes dos primeiros) e saberes práticos (procedimentos decorrentes da própria ação).

Há que se considerar, ainda, que os saberes pedagógicos convertidos em disciplinas se prestam a duas funções. A primeira, a de compor o rol de conhecimentos e práticas da formação do pedagogo stricto sensu (no Brasil denominado, também, ora de técnico, ora de especialista em Educação); a segunda, a de estabelecer os saberes pedagógicos necessários à formação de professores para os vários níveis de ensino, juntamente com os saberes das disciplinas específicas. A despeito do fato de que a legislação educacional brasileira atual sobre a formação de educadores ignore a formação específica do pedagogo ${ }^{12}$, assumimos aqui a posição de que a formação de educadores se realize em dois cursos distintos: o curso de Pedagogia e o curso de formação de professores. $\mathrm{O}$ curso de Pedagogia destina-se à formação de pedagogos especialistas por meio de estudos teóricos de Pedagogia, visando preparar profissionais para a investigação científica e para

12 Libâneo (2006, p. 873) critica essa legislação nos seguintes termos: “O esfacelamento dos estudos no âmbito da ciência pedagógica, com conseqüência (sic) subsunção do pedagogo especialista no professor, e a improcedente identificação dos estudos pedagógicos a uma licenciatura talvez sejam dois dos mais expressivos equívocos teóricos e operacionais da legislação brasileira, no que se refere à formação do pedagogo no Brasil". Também Franco discorda da identificação entre pedagogo e professor. Mantida a formação apenas de professores, excluindo a formação específica do pedagogo, ela pergunta: "Qual será o profissional que está pensando, investigando, propondo, refletindo sobre esta formação? Qual é o profissional que irá direcionar o debate crítico sobre a formação docente; qual será o profissional que irá investigar metodologias de formação? Qual será o profissional que estará

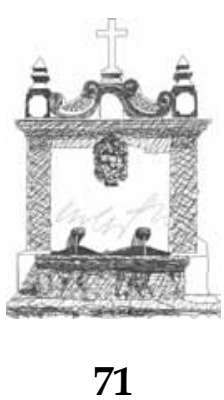

Ano 14 - n. 17 - julho 2011 - p. 55-78 
o exercício profissional no sistema de ensino e em outras instituições educacionais, inclusive as não-escolares. O curso de formação de professores para a Educação Básica, em ligação direta com o curso de Pedagogia, destina-se à formação de professores para a Educação Básica (educação infantil, ensino fundamental e ensino médio).

\section{Considerações finais}

O curso de Pedagogia, portanto, destinado a formar o pedagogo stricto sensu, integra as três dimensões da Pedagogia assinaladas. A dimensão epistemológica fundada na tradição teórica e nos saberes da prática se funde com as condições históricas atuais, para definir os elementos para a elaboração da legislação educacional visando normas para a criação e funcionamento dos cursos de Pedagogia.

Tais elementos, já realçados na produção de diversos educadores ${ }^{13}$, dão as bases para a estruturação da Pedagogia como ciência voltada à prática educativa, contribuindo para que legisladores e intelectuais compreendam a especificidade da Pedagogia e o papel dos pedagogos no aprimoramento da escola brasileira. Desse modo, o curso de Pedagogia tem por especificidade proceder à análise crítica e contextualizada da educação e do ensino como práxis social, formando o profissional pedagogo com formação teórica, científica, ética e técnica para atuar no estudo da teoria pedagógica, na pesquisa educacional e no exercício de atividades pedagógicas específicas.

O posicionamento que nos move é a crença no poder social e político da escola, tendo como base o direito de todos, em condições iguais de oportunidades de acesso aos bens culturais, ao desenvolvimento das capacidades humanas, à formação da cidadania, à conquista da dignidade humana e da liberdade intelectual e política.

\footnotetext{
avaliando, de modo emancipatório e transformador, as práticas educativas e docentes usuais, tirando delas o essencial à reflexão? Quem organizará e articulará os diversos saberes que convergem na prática docente? Quem organizará reflexões sobre a seleção de conteúdos que poderão compor as estruturas curriculares?" (FRANCO, 2006).

13 Especialmente os trabalhos de Pimenta (1996; 1997; 1998), Libâneo (1996; 1997; 1998 a e b)

e Franco $(2001 ; 2003)$.
} 


\section{Referências}

ALTET, M. Les pédagogies de l'apprentissage. Paris: PUF, 1997.

BERTRAND, Y.; HOUSSAYE, J. Didactique et pédagogie:

l'illusion de la différence. L'exemple du triangle. Les sciences de l'éducation pour l'ère nouvelle, Caen: Télé-Université du Québec, n. 1, p. 12-34, 1995.

BRASIL. Conselho Nacional de Educação. Parecer CNE/CP 5, de 13 de dezembro de 2005. Brasília, 2005.

CAMBI, F. História da Pedagogia. São Paulo: Editora Unesp, 1999.

CARR, W. Uma teoría para la educación: hasta una investigación educativa critica. Madrid: Morata, 1996.

CLANDININ, J. Classroom Practice - Teacher Images in Action. London: Falmer Press, 1986.

DEWEY, J. La ciencia de la educación. Buenos Aires: Losada, 1968.

DIAS de CARVALHO, A. Epistemologia das Ciências da Educação. Porto: Afrontamento, 1988.

DURKHEIM, E. Éducation et Sociologie. Paris: PUF, 1985.

ENCONTRO NACIONAL DA ASSOCIAÇÃO NACIONAL PELA FORMAÇÃO DOS PROFISSIONAIS DA EDUCAÇÃO (ANFOPE), 6., 1992, Belo Horizonte. Documento final. Belo Horizonte: ANFOPE, 1992.

FRANCO, M. A. S. Pedagogia como ciência da educação. São Paulo: Cortez, 2008.

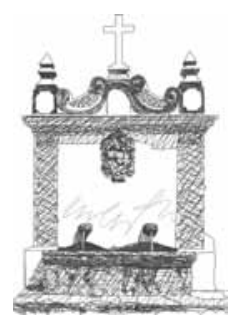


. O curso de Pedagogia em debate: Pedagogia para além dos confrontos. In: GILBERTO, I. (Org.). Universidade em tempo de desafio. Santos: Editora Universitária Leopoldianum, 2006.

A Pedagogia para além dos confrontos. In: FÓRUM DE EDUCAÇÃO: PEDAGOGO, QUE PROFISSIONAL É ESSE?, 2003, Belo Horizonte. Anais... Belo Horizonte: FAE/CBH/ UEMG, 2003b. v. 1.

. Saberes pedagógicos e prática docente. In: ENDIPE:

EDUCAÇÃO FORMAL E NÃO FORMAL, PROCESSOS FORMATIVOS E SABERES PEDAGÓGICOS, 13., 2006, Recife. Anais... Recife: Edições Bagaço, 2006. v. 1., p. 27-50.

HAMELINE, D. Pédagogie. In: CHAMPY, P.; ÉTÉVÉ, C. (Orgs.). Dictionnaire encyclopédique de l'éducation et de la formation. 3a. ed. Paris: RETZ, 2005.

HERBART, J. F. Pedagogia Geral. Lisboa: Fundação Calouste Gulbenkian, 2003.

HOUSSAYE, J.; SOETARD, M.; HAMELINE, D.;FABRE, M. (2002). Manifesto a favor dos pedagogos. Porto Alegre: Artmed, 2004.

JONNAERT, P.; BORGHT, C. V. Criar condições para aprender O modelo socioconstrutivista na formação de professores. Porto Alegre: Artmed, 2002.

KOSIK, K. A dialética do concreto. Rio de Janeiro: Paz e Terra, 1976.

LIBÂNEO, J. C. Fundamentos teóricos e práticos do trabalho docente - Estudo introdutório sobre Pedagogia e didática. 420 p. Tese (Doutorado) - São Paulo, Pontifícia Universidade Católica de São Paulo, 1990. 
. Diretrizes Curriculares da Pedagogia: imprecisões teóricas e concepção estreita da formação profissional de educadores. Educação \& Sociedade, Campinas, v. 27, n. 96, out. 2006.

Educação: Pedagogia e Didática - O campo investigativo da Pedagogia e da Didática no Brasil: esboço histórico e buscas de identidade epistemológica e profissional. In: PIMENTA, S. G. (Org.). Didática e formação de professores: percursos e perspectivas no Brasil e em Portugal. São Paulo: Cortez, 1997.

. Ainda as perguntas: o que é Pedagogia, quem é o pedagogo, o que deve ser o curso de Pedagogia. In: PIMENTA, S. G. (Org.). Pedagogia e pedagogos: caminhos e perspectivas. São Paulo: Cortez, 2002.

. O debate sobre o estudo científico da educação: ciência pedagógica ou ciências da educação? Revista Espaço Pedagogico, Passo Fundo, v. 10, n. 2, jul/dez 2003.

. Pedagogia e pedagogos, para quêe? 8. ed. São Paulo: Cortez, 2005.

LIBÂNEO, J. C.; PIMENTA, S. G. Formação dos profissionais da educação: visão crítica e perspectivas de mudança. Educação $\mathcal{E}$ Sociedade, Campinas, n. 68, dez. 1999.

MARQUES, M. O. A formação do profissional de educação. Ijuí: Ed. Unijuí, 1990.

MIALARET, G. Pédagogie générale. Paris: Presses Universitaires de France, 1991. As ciências da Educação. Lisboa: Moraes, 1976.

NOHL, H. Teoria de la educación. Buenos Aires: Editorial Losada, 1948.

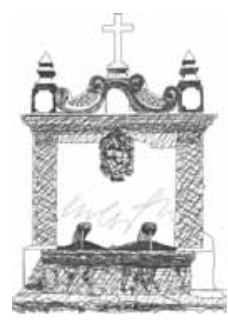


PIMENTA, S. G. (Org.) Pedagogia e pedagogos: caminhos e perspectivas. São Paulo: Cortez, 2002b.

( (Coord.). Pedagogia, ciência da educação? São Paulo: Cortez, 1996.

. Formação de professores - saberes da docência e identidade do professor. In: PIMENTA, S. G. (Org.). Saberes pedagógicos e atividade docente. São Paulo: Cortez, 1999.

. Para uma re-significação da Didática: ciências da educação, Pedagogia e Didática (uma revisão conceitual e uma síntese provisória). In: PIMENTA, S. G. (Org.). Didática e Formação de Professores - percursos e perspectivas no Brasil e em Portugal. São Paulo. Cortez, 1997.

PIMENTA, S. G.; GHEDIN, E. (Orgs). Professor reflexivo no Brasil - gênese e crítica do conceito. São Paulo: Cortez, 2002a.

SARRAMONA, J.; MARQUES, S. Qué es la Pedagogia? Una resposta actual. Barcelona: Ediciones CEAC, 1985.

SAVIANI, D. Escola e democracia. São Paulo: Cortez/Autores Associados, 1983.

SCHMIED-KOWARZIK, W. Pedagogia dialética. São Paulo: Brasiliense, 1983.

SÖETARD, M. Ciência(s) da educação ou sentido da educação? A saída pedagógica. In: HOUSSAYE, J.; SOETARD, M.; HAMELINE, D.; FABRE, M. Manifesto a favor dos pedagogos. Porto Alegre: Artmed, 2004.

SUCHODOLSKI, B. Tratado de Pedagogía. Barcelona, Ediciones Península, 1979. 
La Educación Humana del Hombre. Barcelona: Ed. Laia, 1977.

VISALBERGHI, A. Pedagogia e scienze dell'educazione. Milano: Arnoldo Mondadori Editore, 1983.

WILLMANN, O. A ciência da educação. Porto Alegre: Globo, 1970.

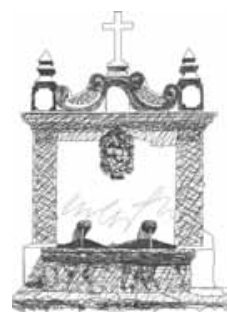




\title{
Constitutive dimensions of Pedagogy as a field of knowledge
}

\begin{abstract}
The text discusses the epistemological specificity of the scientific and professional field of Pedagogy, defining it as the theory and practice of Education, including Education in its broadest and multidimensional sense. Thus, the variety of educational practices in society results in a variety of teaching practices, including schooling. It is claimed the distinction between pedagogy and didactics, that a broader concept than this, where the teaching is presented as a peculiar mode of pedagogical activity. Based on the understanding of educational practice - as an object of science teaching - as an intentional action, reflective and transformative praxis that are spelled out three dimensions of Pedagogy, the epistemological dimension; the practice one and it disciplinary dimension.
\end{abstract}

Keywords: epistemology of Pedagogy; educational practice; Pedagogy and Didactics; pedagogical theory. 